\title{
1.5 Роль сывороточных биомаркеров в течении кардиомиопатий у детей
}

Болезни сердечно-сосудистой системы имеют особую значимость, связанную не только с их широким распространением, сколько с той ролью, которую эти заболевания играют в смертности, инвалидизации детей и в формировании заболеваемости взрослых [47, 48]. По данным экспертов Всемирной организации здравоохранения, «..отрицательная динамика показателей здоровья населения зафиксирована даже в странах с высоким уровнем жизни: отмечается рост онкологической и эндокринной патологии, а также заболеваний сердечно-сосудистой системы (ССС), среди которых сердечно-сосудистые заболевания занимают 1-е место в структуре смертности среди взрослого населения» [49, 50]. Согласно независимым многоцентровым исследованиям, дети относятся к группе риска развития кардиоваскулярной патологии, именно в детском возрасте идет формирование основных факторов риска развития сердечно-сосудистых событий, реализация которых ухудшает отдаленный прогноз заболевания, снижая качество жизни и социальную адаптацию в последующие возрастные этапы [51, 52, 53].

В этом плане одну из лидирующих позиций у детей занимают кардиомиопатии, которые относятся к тяжелым, непрерывно прогрессирующим некоронарогенным заболеваниям миокарда, характеризующимся разнообразием причин, симптомов и проявлений, а также и высокой летальностью $[47,48,54]$.

КМП у детей имеют не только медицинскую и социальную значимость, но и приносят экономический ущерб, связанный с тяжестью заболевания и его последствиями $[55,56,57,58]$

В мире проводятся широкомасштабные научные исследования, направленные на совершенствование диагностики, дифференциации, прогноза и лечения сердечно-сосудистых заболеваний у детей. Кардиомипатии, являясь одной из представительной групп некоронарогенных заболеваний миокарда, отличаются наиболее тяжелым течением с развитием сердечной 
недостаточности, нередко закончивающейся внезапной сердечной смертью [59, $60,61]$.

Повышенный интерес к проблеме изучения заболеваний миокарда объясняется необходимостью дальнейшего изучения этиологии и патогенеза; многообразием и неспецифичностью их клинических проявлений, значительными диагностическими и терапевтическими трудностями на протяжении многих лет, что обусловлено не только высокой смертностью, но и отсутствием единых подходов к диагностике и лечению больных с этой тяжелой патологией. КМП вносят значительный вклад в структуру сердечной недостаточности [55, 62, 63, 64, 65].

В последние годы наметилась тенденция к росту КМП у детей, что объясняется не только истинным увеличением случаев КМП, но и повышением качества диагностики с применением высокотехнологичных методов визуализации сердца, а также, с эволюцией взглядов на кардиомиопатии, как на нозологические единицы $[66,67]$.

У детей при проведении функциональных методов визуализации сердца не всегда возможно определение диагностически значимых признаков КМП. В этом случае для диагностики и прогноза СН в качестве альтернативного и дополнительного диагностического подхода рекомендуется определение в крови биомаркеров. Данный метод широко применяется во взрослой практике и зарекомендовал себя безопасным и объективным средством диагностики и прогноза прогрессирования и осложнений КМП [68, 69, 70, 71, 72, 73].

Braunwald E. в 2008 году предложил классификацию биомаркеров, имеющих значение в диагностике и лечении пациентов с CH: маркеры воспаления (C реактивный протеин, фактор некроза опухоли альфа, аполипопротеин 1, интерлейкины 1, 6 и 18), маркеры оксидативного стресса (окисленные липопротеины низкой плотности, миелопероксидаза, малондиальдегид и др.), маркеры ремоделирования внеклеточного матрикса (металлопротеиназы и их ингибиторы, проколлаген тип I и III и др.), нейрогормоны (катехоламины, ренин, альдостерон, эндотелин 1 и др.), маркеры 
повреждения кардиомиоцитов (тропонины, креатинфосфокиназа МВ (КФК МВ), белок, связывающий жирные кислоты и др.), маркеры миокардиального стресса (натрийуретические пептиды, проадреномедуллин, растворимая форма ST2 рецептора и др.) [74]. В настоящее время используются биомаркеры развития и прогрессирования $\mathrm{CH}$, которые отражают такие патофизиологические процессы, как апоптоз, воспаление и ремоделирование внеклеточного матрикса $[72,75,76$, $77,78]$.

Концепция молекулярных биомаркеров получила широкое развитие в последнее десятилетие. Использование биомаркеров вносит вклад в понимание патогенетических механизмов сердечно-сосудистых заболеваний и сердечной недостаточности [73]. Они являются надежным, безопасным и объективным средством диагностики и стратификации риска неблагоприятных событий, дополняющим клинические и инструментальные данные и отражающим особенности механизмов развития и прогрессирования заболевания у конкретного пациента $[71,79,80,81]$.

С целью изучения значения некоторых сывороточных биомаркеров в развития и прогнозирования КМП и сердечной недостаточности у детей были определены представители 3 групп биомаркеров (повреждения кардиомиоцитов, нейрогормонов и воспаления).

1.5.1. Роль маркеров повреждения кардиомиоцитов в развитии и прогнозе сердечной недостаточности при кардиомиопатиях у детей.

В последние годы в кардиологии все большее значение придается определению компонентов тропонинового комплекса кардиомиоцитов как наиболее чувствительному и специфичному биохимическому маркеру некроза миокарда $[71,82]$. Тропонины (I, T и C) в соотношении 1:1:1 входят в состав тропонинового комплекса, связанного с тропомиозином. Все три тропонина участвуют в кальций-зависимой регуляции акта сокращения-расслабления.

Имеются данные, что наследственные формы ГКМП, ДКМП и РКМП обусловлены мутациями сердечных тропонинов Т, I и С. На сегодняшний день обнаружено более 100 различных мутаций во всех 3 изоформах тропонина и 
число их продолжает расти, описываются новые случаи [69, 83]. У детей относительно недавно обнаружена мутация TNNT2 по типу двойной делеции аминокислот в положении 100 и 101 ( $\Delta \mathrm{N} 100 / \Delta \mathrm{E} 101)$, при которой была повышена чувствительность кардиомиоцитов к ионам кальция и нарушены белок-белковые взаимодействия между миофиламентами [84].

Кардиальный тропонин С в противоположность тропонинам Т и I совершенно идентичен по структуре мышечному тропонину С и, следовательно, не является кардиоспецифичным протеином. В настоящее время определение компонентов тропонинового комплекса кардиомиоцитов уже достаточно широко используется в кардиологической практике в основном для диагностики инфаркта миокарда (ИМ). Установлено, что тропонины $\mathrm{T}$ и I могут расцениваться и как поздние диагностические маркеры, позволяющие выявить «пропущенный» ИМ. Такая чувствительность тропонинов при высокой степени специфичности позволяет рассматривать эти миокардиальные маркеры как «золотые стандарты» в диагностике ИМ, имеющие явные преимущества перед КФК-МВ и ЛДГ. В 2000 г. ведущие кардиологические сообщества Европы и США утвердили тропонин как главный диагностический критерий ИМ [85].

В педиатрии определение тропонинов стали применять в последние несколько лет и, в основном, в неонатологии [86, 87, 88]. Исследования проводились у недоношенных и маловесных новорожденных с патологией ЦНС. Критерием исключения являлись врожденные пороки сердца (ВПС), нарушения сердечного ритма, генетические аномалии. Повышение уровня тропонинов отмечалось у детей в тяжелом состоянии (внутрижелудочковые кровоизлияния, длительная ИВЛ и др.). При СС3 у детей определение тропонина Т проводилось при ВПС. У данной группы пациентов в первые дни жизни отмечены повышенные значения тропонина Т и снижение его уровня на 2-3-й неделе [89]. Выявлено повышение уровня тропонина I у детей в возрасте от 3 до 16 лет с явлениями недостаточности кровообращения (НК) ІІБ-ІІІ степени с летальным исходом $[90,91]$. 
Учитывая, что к биохимическим маркерам повреждения миокарда относят среди прочих кардиоспецифический белок - тропонин-I, мы нашли целесообразным из трех тропонинов (I, T и C), входящих в состав тропонинового комплекса, провести исследования по определению степени значимости тропонина-I в качестве прогностического маркера КМП у детей.

Таблица 1

Показатели тропонина-I в зависимости от варианта КМП

\begin{tabular}{|l|c|c|c|c|c|c|}
\hline \multicolumn{1}{|c|}{ Показатель } & ДКМП & ГКМП & РКМП & $\mathrm{P}_{1}$ & $\mathrm{P}_{2}$ & $\mathrm{P}_{3}$ \\
\hline $\begin{array}{l}\text { Тропонин -I, } \\
(0-0,5 \text { нг/мл) }\end{array}$ & $0,2 \pm 0,019$ & $0,4 \pm 0,038$ & $0,4 \pm 0,05$ & $>0,05$ & $>0,05$ & $>0,05$ \\
\hline
\end{tabular}
допустимыми значениями ( $<0,001)$; $\mathrm{P}_{1}$ - достоверность разницы между показателями детей с ДКМП и ГКМП; Р 2 - достоверность разницы между показателями детей с ДКМП и РКМП; Р 3 - достоверность разницы между показателями детей с ГКМП и РКМП; .

Оценка состояния миокарда, включающая изучение содержания тропонина-I у детей с кардиомиопатиямив зависимости от варианта КМП, показала, что уровень тропонина-I независимо от нозологии достоверно не отличался от нормативных референсных показателей (табл. 1).

Таким образом, полученные результаты свидетельствуют, что тропонин-I не может быть использован в качестве биомаркера для диагностики и оценки течения КМП независимо от варианта КМП.

1.5.2. Роль нейрогормонального маркера - пептида эндотелин 1 в развитии сердечной недостаточности при кардиомиопатиях у детей.

В патогенезе СН при КМП и других СС3 существенную роль играет нейроэндокринная активация катехоламинов, натрийуретических пептидов и компонентов системы ренин-ангиотензина. Установлено, что при СН у больных с ДКМП изменена экспрессия генов многих классов, что ведет к изменению организации цитоскелета и миофибрилл, нарушению передачи сигналов, обмена протеинов и энергетики в миокарде [92, 93, 94, 95]. 
Эндотелин относится к числу биологически активных бициклических полипептидов широкого спектра действия и является одним из наиболее значимых регуляторов функционального состояния эндотелия сосудов [96, 97, 98].

Самым распространенным из семейства эндотелинов, а также самым мощным вазоконстриктором, который в 10 раз сильнее ангиотензина II и в 100 раз превышает эффект норадреналина, является эндотелин-1 [97, 99]. Установлено, что данный белок имеет большое сходство с токсическим компонентом яда пауков и некоторых видов змей. Пептид (сарафотоксин), полученный из яда змеи Atractaspis engaddensis имеет структурное и функциональное сходство с эндотелинами. При попадании сарафотоксина в кровь жертвы возникает коронароспазм, вплоть до остановки сердца [94].

Определение концентрации в плазме крови эндотелина-1 помогает установить диагноз СН на ранних стадиях заболевания, а концентрация церебрального натрийуретического пептида в крови является предиктором риска летального исхода у больных ДКМП [94].

В настоящее время известно, что вазоконстрикторный эффект, увеличение частоты и силы сердечных сокращений (хроно- и инотропные эффекты) эндотелина-1, а также потенцирование им роста и дифференцировки тканей реализуются путем активации двух типов рецепторов - ЭТ-А и ЭТ-В. ЭТ-А обладает высокой аффинностью к эндотелину-1 и эндотелину-2. У ЭТ-В нет предпочтительности, зато он имеет два подтипа - ЭТ-В1 и ЭТ-В2 $[100,101]$. Около десяти лет назад выделен еще один тип рецепторов эндотелина - ЭТ-С. Его структура и роль до конца не изучены. Но предполагается, что действие эндотелина-3 происходит именно через рецепторы ЭТ-С [102]. Подтипы рецепторов по-разному локализованы в сосудистой системе: ЭТ-А обнаруживаются в гладкомышечных клетках сосудов, кардиомиоцитах, в ткани мозга и в желудочно-кишечном тракте; ЭТ-В находятся в гладкомышечных клетках, в венечных сосудах, кардиомиоцитах, клетках юкстагломерулярного аппарата и в подвздошной кишке [94]. 
Существуют прямые и не прямые эффекты эндотелинов. К прямым эффектам относится воздействие на гладкие мышцы сосудов. При их взаимосвязи происходит вазоконстрикция, активация митогенеза, пролиферация клеток и фиброз интимы с повышением жесткости сосудов [97, 103]. К опосредованным - высвобождение из эндотелия вазоактивных факторов (оксида азота, простациклина и натрийуретического пептида предсердий), приводящих к релаксации сосудов [102]. Кроме этого, эндотелины влияют на секрецию гормонов гипофиза и надпочечников, подавляют эффекты вазопрессина в почках, а также увеличивают реакции сердца на симпатические стимулы, повышают сосудистую проницаемость, активируют нейтрофилы и тучные клетки. Эндотелины причастны к иммуномодулирующим эффектам, активируя Т-лимфоциты в вилочковой железе и усиливая иммунный ответ. Следует отметить о роли эндотелина-1 в качестве ингибитора апоптоза $[94,104]$.

Эндотелин-1 рассматривают, прежде всего, как маркер и предиктор тяжести и исхода ИМ и ИБС [101]. Следствием нарушений метаболизма и сократительной функции миокарда являются изменения сердечного ритма, приводящие к развитию фибрилляций [104]. Считается, что эндотелин-1 причастен к легочной гипертензии, атеросклеротическому повреждению сосудов, послеродовым сосудистым осложнениям, поражению почек при гломерулонефрите, ишемическим повреждениям мозга, сахарному диабету [105, $106,107]$.

ЭТ-1 обладает широким спектром провоспалительных эффектов, выходящих за рамки его вазоконстрикторной активности. Показано, что гиперпродукция ЭТ-1 приводит к усилению апоптоза кардиомиоцитов и может способствовать увеличению постнагрузки ЛЖ, снижению сердечного выброса, а также индуцирует процессы ремоделирования миокарда и способствует прогрессированию СН [94].

Подобное многообразие функций эндотелина, а также недостаточная изученность данного пептида позволяет считать исследование по определению 
его в диагностической и прогностической значимости при КМП у детей актуальным.

Эндотелин относится к числу биологически активных бициклических полипептидов широкого спектра действия, различают три изоформы эндотелина: эндотелина-1, эндотелин-2 и эндотелин-3 [48, 94]. На сегодняшний день эндотелин-1 является одним из наиболее значимых регуляторов функционального состояния эндотелия сосудов [94]. Определение концентрации в плазме крови эндотелина-1 помогает установить диагноз сердечной недостаточности на ранних стадиях заболевания.

На основании этих данных мы нашли целесообразным определить степень значимости эндотелина-1 в качестве прогностического биомаркера КМП и сердечной недостаточности у детей.

Результаты наших исследований выявили высокие показатели эндотелина1 у больных с выраженной $\mathrm{CH}$, т.е. уровень эндотелина-1 достоверно увеличивается по мере прогрессирования заболевания, что свидетельствует о значимости данного показателя в прогнозировании течения и исхода КМП у детей (рис.1).

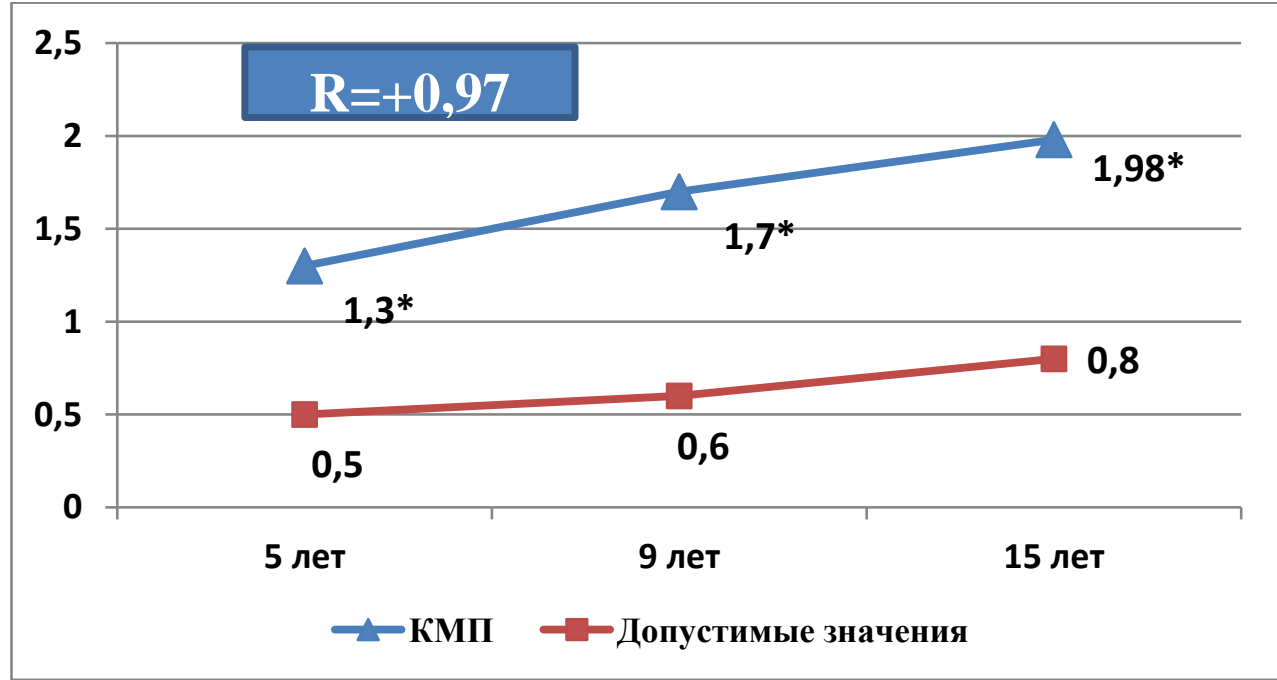

Примечание: *- достоверность разности между показателями детей с КМП и допустимыми значениями.

Рис. 1. Показатели эндотелина-1 в зависимости от давности заболевания.

Как видно из рис.1, у больных с давностью заболевания 5 лет уровень эндотелина-1 в среднем составил 1,3 $\pm 0,08$ фмоль/л, что всего в 1,3 раза 
превышает верхнюю границу допустимых значений, больных с давностью заболевания 9 лет, средний показатель уровня эндотелина-1 составил 1,7士 0,1 фмоль/л и превысил референтные значения в 1,7 раза, а у больных с давностью

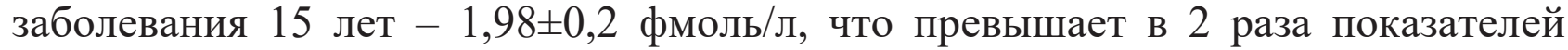
нормы. Корреляционный анализ между давностью КМП, степени тяжести СН и уровнем эндотелина-1 выявил наличие сильной прямой корреляционной связи $(\mathrm{r}=+0,97)$. В связи с этим, уровень эндотелина-1 можно расценивать прогностическим критерием течения и исхода КМП.

В дальнейшем для оценки состояния миокарда у детей с КМП нами был проведен анализ эндотелина-1 в зависимости от варианта КМП свидетельствовал о том, что при кардиомиопатиях уровень эндотелина-1 был повышенным при всех формах кардиомиопатий (табл. 2). Уровень эндотелина-1 был выше у детей с ГКМП (p<0,05), по сравнению с показателем детей с ДКМП и РКМП.

Таблица 2

Показатели эндотелина-1 в зависимости от варианта КМП

\begin{tabular}{|l|c|c|c|c|c|c|}
\hline \multicolumn{1}{|c|}{ Показатели } & ДКМП & ГКМП & РКМП & $\mathrm{P}_{1}$ & $\mathrm{P}_{2}$ & $\mathrm{P}_{3}$ \\
\hline $\begin{array}{l}\text { Эндотелин- } 1, \\
(0,1-1,0 \text { фмоль/л) }\end{array}$ & $1,75 \pm 0,1^{*}$ & $1,61 \pm 0,2^{*}$ & $1,67 \pm 0,3^{*}$ & $<0,05$ & $<0,05$ & $>0,05$ \\
\hline
\end{tabular}

Примечание:*- достоверность различий между показателями детей с КМП и допустимыми значениями $(\mathrm{P}<0,001) ; \mathrm{P}_{1}$ - достоверность разницы между показателями детей с ДКМП и ГКМП; Р 2 - достоверность разницы между показателями детей с ДКМП и РКМП; Р - достоверность разницы между показателями детей с ГКМП и РКМП .

На основании этого можно заключить, что эндотелин-1 можно расценивать высокоспецифичным биомаркером поражения миокарда, а возрастание его активности по мере увеличения давности заболевания - критериями прогрессирования СН и исхода кардиомиопатий у детей.

1.5.3. Иммунологические аспекты в прогрессировании сердечной недостаточности при кардиомиопатиях у детей

В последние годы предложена новая концепция прогрессирования $\mathrm{CH}$, в основе которой лежит представление об иммунной активации и системном воспалении как о маркерах неблагоприятного прогноза и высокого 
кардиоваскулярного риска. Согласно этой концепции, происходит увеличение синтеза провоспалительных цитокинов, определяющих эволюцию дисфункции ЛЖ $[108,109,110,111]$.

Цитокины, являясь регулятором защитных реакций организма, усиливают эффекторные механизмы элиминации чужеродного антигена, регулируют воспаление и регенерацию [112]. Ряд цитокинов обладает способностью инициировать и стимулировать воспалительные реакции (IL-1, IL-6, IL-8, IL-12, IL-16, IL-18, TNF- $\alpha$, IFN- $\alpha$, IFN- $\gamma$ ), тогда как другие (IL-4, IL-10, IL-13) подавляют их $[108,113,114]$. Цитокины способны существовать не только в форме циркулирующих молекул, но и в связанной форме (IL- $1 \alpha$, TNF- $\alpha$ ). В целом цитокины - это сигнальные молекулы, играющие ключевую роль в иммунной системе в норме и при патологии [112]. Формирование и развитие СН тесно связано с нарушением сложных процессов цитокин-индуцированной передачи внеклеточной информации внутрь кардиомиоцита. Цитокины, регулируя синтез белков и фосфолипидов, способны активировать внутриклеточные сигнальные системы, включая апоптоз, систему регуляции внутриклеточного кальция и тем самым, изменять процессы сокращения и расслабления миокарда. $[115,116]$.

Неспецифическая активация макрофагов и моноцитов в плазме и межтканевой жидкости является индуктором синтеза провоспалительных цитокинов, определяющих степень дисфункции ЛЖ. Предполагается, что провоспалительные цитокины играют важную роль в прогрессировании $\mathrm{CH}$, определяя состояние структурных белков миофибрилл и цитоскелет кардиомиоцита $[115,117]$

Содержание цитокинов в плазме крови больных с ХCH, независимо от ее этиологии, значительно превышает нормальные значения [108, 117]. Усиление застоя и нарастающая гипоксия периферических тканей и самого миокарда, свойственные ХCH, вполне могут стать первопричиной активации иммунной системы и приводить к росту TNF- $\alpha$ и других провоспалительных цитокинов. Такая «последовательность» событий косвенно подтверждается прямо пропорциональной зависимостью между уровнем TNF- $\alpha$ и тяжестью XCH: чем 
выше ХCH, тем более выражена реакция иммунной системы и выше уровень цитокинов. И, наоборот, уменьшение степени гипоксии понижает активность иммунного ответа [115, 118$]$.

На сегодняшний день очевидно, что это влияние складывается по крайней мере из четырех ключевых составляющих [118]: 1) отрицательного инотропного действия; 2) ремоделирования сердца (необратимая дилатация полостей и гипертрофия кардиомиоцитов; 3) нарушения эндотелий-зависимой дилатации артериол; 4) усиления процесса апоптоза кардиомиоцитов и клеток периферической мускулатуры.

Известно [118], что цитокины также могут играть важную роль в реализации процессов гиперкоагуляции крови, нарушений регулирования сосудистого тонуса, развития острых коронарных синдромов, индукции метаболических процессов в скелетных мышцах и прогрессирования мышечной дистрофии (развитие синдрома кардиальной кахексии). Предполагается, что негативное действие цитокинов лежит в основе таких характерных гемодинамических признаков ХСН, как низкий сердечный выброс и высокое внутрисердечное давление, а в сочетании с нарушением сосудодвигательной функции эндотелия резистивных сосудов - быть причиной гипотонии, свойственной поздним стадиям сердечной недостаточности, а также снижения толерантности к физической нагрузке и уменьшения силы и выносливости скелетной мускулатуры. Наиболее важными для формирования синдрома ХСН являются «долговременные» эффекты провоспалительных цитокинов, проявляющиеся постепенным разрушением внеклеточного коллагенового матрикса миокарда, дилатацией желудочков и гипертрофией кардиомиоцитов [115, 118$]$.

Таким образом, провоспалительные цитокины являются наиболее важным классом биологически активных веществ, оказывающих иммунное и/или воспалительное действие и имеющих отношение к сердечной недостаточности. К основным провоспалительным цитокинам относятся фактор некроза опухоли$\alpha(\mathrm{TNF}-\alpha)$, интерлейкин 1 (IL-1 $\beta)$ и IL-6 [115, 117, 118]. 
TNF- $\alpha$ является наиболее «важным» маркером развития СН. Прямая связь TNF- $\alpha$ с синдромом CH была установлена в 1990 г. Levine и соавт. [119] впервые показали, что уровень TNF- $\alpha$ в сыворотке больных с тяжелой CH (ФК III-IV по NYHA) на порядок выше, чем у здоровых лиц: Причем повышение активности TNF- $\alpha$ было более выраженным у пациентов с более тяжелыми клиническим и проявлениями декомпенсации, большей степенью кахексии (массой тела $82 \%$ от идеального) и повышенной активностью PAAC $[108,115]$. Влияние TNF- $\alpha$ на прогрессирование СН реализуется путем прямого повреждающего действия на кардиомиоциты, индуцируя процесс их запрограммированной гибели (апоптоз). Кроме того, TNF- $\alpha$ усиливает процессы окислительного стресса кардиомиоцитов [120]. TNF- $\alpha$ проявляет свою биологическую активность после связывания со специфическими мембранными рецепторами $[108,115]$.

Избыточная продукция TNF- $\alpha$ вызывает расстройства гемодинамики и оказывает цитотоксический эффект на клетки организма $[115,121]$.

TNF- $\alpha$ усиливает пролиферацию T- и В-клеток, цитотоксических лимфоцитов, фагоцитоз, индуцирует синтез IL-1 $\beta$, IL-6, IL-2, хемоаттрактантов, адгезивных молекул, острофазных белков, активирует фибробласты, синтез коллагена и коагуляцию. TNF- $\alpha$ стимулирует адгезию моноцитов и лимфоцитов (in vitro) к мезангиальным клеткам, индуцируя экспрессию ICAM-1 [115].

Интерлейкин-1 (IL-1 $\beta$ ) - провоспалительный цитокин, имеющий отношение к $\mathrm{CH}$, играет центральную роль в локальном исистемном, остром и хроническом воспалении. IL-1 $\beta$, кроме эндотелиальных клеток, синтезируется также макрофагами, моноцитами, нейтрофилами, глиальными клетками, фибробластами, Т- и В-лимфоцитами. Как сигнальная молекула, обеспечивает межклеточные взаимодействия, которые в совокупности приводят к формированию воспалительной реакции посредством: экспрессии белков острой фазы воспаления в гепатоцитах, активации нейтрофилов, воздействия на Tхелперы и стимуляции каскада провоспалительных субстанций, прямого провоспалительного влияния на эндотелиальные гладкомышечные клетки и макрофаги, усиления адгезии лейкоцитов к эндотелию, обеспечения ихмиграции 
через сосудистую стенку, стимуляции экспрессии адгезивных молекул $[115,117$, $118]$.

Известно, что провоспалительный цитокин IL-1 $\beta$ продуцируется клетками воспаления, вызывает высвобождение и экспрессию других воспалительных медиаторов (цитокинов/факторов роста, хемокинов, биоактивных липидов, металлопротеиназ и активных радикалов кислорода, адгезивных рецепторов), пролиферацию резидентных клеток, накопление экстрацеллюлярного матрикса $[117,121]$.

У больных с XCH также отмечаются изменения концентрации IL-6. Интерлейкин-6синтезируется многими клетками (макрофаги, моноциты, Т- и Влимфоциты и др.), является одним из мощнейших факторов, вызывающих дисфункцию эндотелия. Его продукция стимулируется IL-1 $\beta$ и TNF- $\alpha$. Гиперэкспрессия IL-6 выявляется в кардиомиоцитах на фоне гипоксического стресса. Кроме того, IL-6 вызывает отрицательный инотропный эффект, гиперэкспрессияIL-6 рецепторов приводит к гипертрофии миокарда. Увеличение концентрации IL-6 являлось маркером неблагоприятного прогноза и коррелировало с функциональным классом ХСН $[115,118,121]$.

Представляются важными и данные о том, что повышенная экспрессия медиаторов воспаления (TNF- $\alpha$, IL-1 $\beta$, IL-6, молекулы адгезии) наблюдается не только в крови, но и в миокарде $[115,117]$. Усиленная миокардиальная экспрессия цитокинов, обнаруживаемая при дисфункции миокарда, предполагает центральную роль цитокинов в развитии процессов ремоделирования миокарда и возникновении ХCH.

Предположение о способности цитокинов, в частности TNF- $\alpha$, индуцировать ремоделирование миокарда с прогрессирующим снижением его сократимости, подтверждается данными литературы [117, 122], в которых установлена взаимосвязь TNF- $\alpha$ c гемодинамическими параметрами и продемонстрирована его гиперэкспрессия у больных с дезадаптивной формой ремоделирования миокарда. 
Молекулярные механизмы развития цитокин-индуцируемого ремоделирования миокарда еще не ясны, но, возможно, определяются синергической активностью цитокинов в отношении экспрессии «индуцируемой» формы синтазы оксида азота (NoS2) в кардиомиоцитах и эндотелиоцитах. Получены данные, что «индуцируемая» синтаза оксида азота ответственна за состояние миокарда, именуемое «гибернацией». В связи с этим определенный интерес представляет изучение роли провоспалительных цитокинов в процессах деструкции миокардиальной ткани у детей на разных стадиях развития СН [118].

Существует несколько взаимосвязанных компонентов иммунной системы, которые могут быть задействованы в патогенезе сердечной недостаточности, и главными из них являются провоспалительные цитокины (TNF- $\alpha$, IL-1 $\beta$, IL-6), молекулы адгезии, аутоантитела, оксид азота, эндотелины [115, 119].

В настоящее время используются биомаркеры развития и прогрессирования сердечной недостаточности, которые отражают такие патофизиологические процессы, как апоптоз, воспаление и ремоделирование внеклеточного матрикса [120]. Наиболее важным классом биологически активных веществ, оказывающих иммуновоспалительное действие, являются провоспалительные цитокины.

Сравнительный анализ содержания провоспалительных цитокинов у больных с кардиомиопатиями выявил выраженные изменения продукции IL-1 $\beta$ и IL-6 в зависимости от стадии сердечной недостаточности. Как видно из табл.3, у обследованных детей получены достоверные отличия концентраций указанных показателей от нормальных значений. Установлена незначительная гиперпродукция IL-1 $\beta$ у пациентов с СН IIБ-III ст. при ДКМП, с CH IIБ ст. при ГКМП. У детей с ДКМП и ГКМП отмечена максимальная концентрация IL-6 и TNF- $\alpha$ при CH IIA стадии и выраженной СН IIБ-III стадии при ДКМП. 
Таблица 3

Содержание интерлейкинов при различных стадиях СН у детей с кардиомиопатиями

\begin{tabular}{|l|c|c|c|}
\hline Группы детей & IL-1 $\beta$, пг/мл & IL-6, пг/мл & TNF- $\alpha$, пг/мл \\
\hline ДКМП,СН І ст. & $1,5 \pm 0,3^{*}$ & $6,8 \pm 1,4^{\wedge}$ & $6,9 \pm 0,2^{* \wedge}$ \\
\hline ДКМП,СНІА & $1,6 \pm 0,4$ & $21,7 \pm 1,8^{*} \wedge$ & $11,5 \pm 0,3^{*}$ \\
\hline ДКМП, СН ІІБ-III ст. & $2,9 \pm 0,2$ & $30,7 \pm 4,3^{* \wedge}$ & $12,6 \pm 0,4^{*}$ \\
\hline ГКМП, СН І ст. & $1,9 \pm 0,2$ & $9,88 \pm 0,8^{*}$ & $9,8 \pm 0,4^{*}$ \\
\hline ГКМП, СН ІІА ст. & $2,8 \pm 0,4$ & $14,75 \pm 1,5^{*}$ & $11,9 \pm 1,1^{*}$ \\
\hline ГКМП, СН ІІБ ст. & $3,1 \pm 0,3^{*}$ & $26,3 \pm 2,3^{*}$ & $13,7 \pm 1,4^{*}$ \\
\hline Референсные значения & $0,00-2,34$ & $0,00-2,13$ & $2,28-7,81$ \\
\hline Корреляционные взаимосвязи & $\mathrm{R}=+0,89$ & $\mathrm{R}=+0,99$ & $\mathrm{R}=+0,73$ \\
\hline
\end{tabular}

Примечание: * - достоверность относительно показателей здоровых детей; ^ достоверность разницы между показателями при различной стадии СН в зависимости от формы КМП.

Высокий уровень провоспалительных цитокинов, особенно TNF- $\alpha$ оказывает повреждающее действие на миокард. Данный цитокин способен индуцировать процесс запрограмированной гибели кардиомиоцитов, под влиянием гиперпродукции TNF- $\alpha$ происходит активация металлопротеиназ, индуцирующих разрушение фибриллярного коллагенового матрикса, что способствует ремоделированию миокарда и формирования отрицательного инотропного эффекта $[120,123]$.

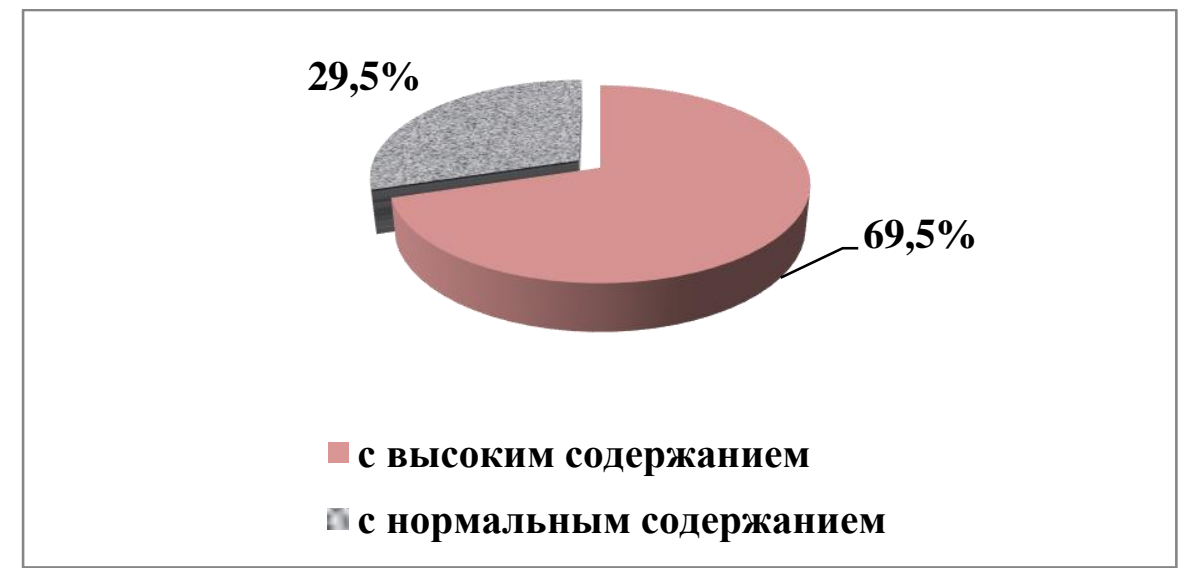

\section{Рис.2. Количество детей с КМП с высоким и нормальным содержанием TNF- $\alpha$ в сыворотке крови}

В исследованиях выявлена способность самих кардиомиоцитов к продукции фактора некроза опухоли (TNF- $\alpha$ ), при этом, количество цитокина находится в прямой зависимости от степени напряжения миокарда. Длительная активация симпатоадреналовой системы приводит к перегрузке митохондрий 
кардиомиоцитов кальцием, что замедляет процессы рефосфорилирования аденозиндифосфата и нарушает процессы сократимости и расслабления [115]. Изучение содержания TNF- $\alpha$ в сыворотке крови у детей с КМП показало его значительное повышение относительно нормы. Высокий уровень содержания TNF- $\alpha$ был выявлен у 69,5\% больных (рис.2).

Так, если умеренная гипоксия сопровождается значительным повышением уровня TNF- $\alpha$ в сыворотке крови, то в случае тяжелой гипоксии у этих детей его уровень был повышен $(\mathrm{p}<0,05)$.

Так, при умеренной гипоксии уровень TNF- $\alpha$ в сыворотке крови колебался от 8 до 12,4 пг/мл и среднее содержание его было выше $(9,2 \pm 0,87$ пг/мл, p<0,001) показателей нормы (2,28-7,81 пг/мл), в случае тяжелой гипоксии у этих детей средний уровень TNF- $\alpha$ был достаточно высоким $(15,7 \pm 1,2$ пг/мл, p $<0,01)$ и колебался в пределах 12,7-17,5 пг/мл (рис.3). Более выраженное повышение TNF- $\alpha$ отмечалось ДКМП с сердечной недостаточностью IIБ - III степени $(17,1 \pm 1,6$ пг/мЛ, $\mathrm{p}<0,01)$.

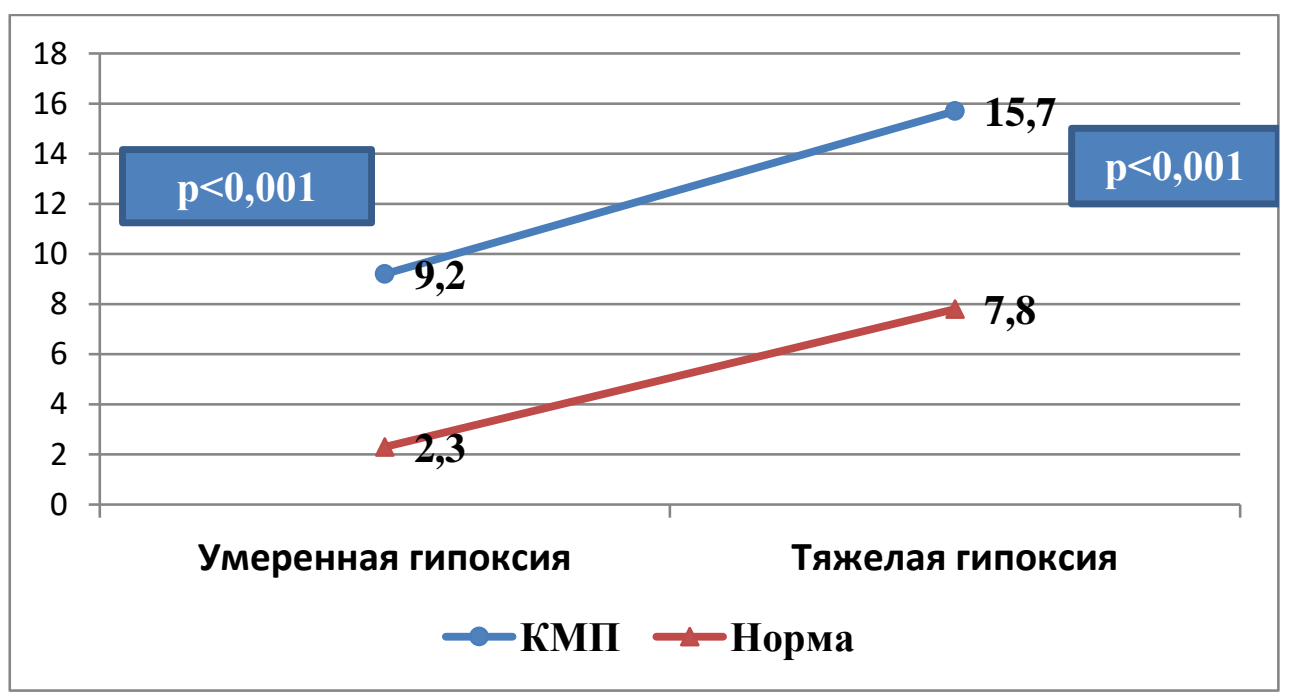

Примечание: р-достоверность различий между показателями детей с КМП и нормой.

\section{Рис.3. Уровень TNF- $\alpha$ у детей с кардиомиопатиями в зависимости от степени гипоксии}

Таким образом, усиление застоя и нарастающая гипоксия периферических тканей и самого миокарда, свойственные $\mathrm{CH}$, вполне могут стать первопричиной активации иммунной системы и приводить к росту TNF- $\alpha$ и других провоспалительных цитокинов. Такая "последовательность" событий косвенно 
подтверждается прямопропорциональной зависимостью между уровнем TNF- $\alpha$ и тяжестью $\mathrm{CH}$ : чем выше стадия $\mathrm{CH}$, тем более выражена реакция иммунной системы и выше уровень цитокинов. И, наоборот, уменьшение степени гипоксии понижает активность иммунного ответа.

Изучение молекулярных механизмов управления процессами неоваскуляризации также представляет собой одну из наиболее актуальных проблем. Многие патологические и физиологические процессы в органах и тканях протекают с участием семейства факторов роста эндотелия сосудов (vascular endothelial growth factor - VEGF), которое включает VEGF A, VEGF B, VEGF C, VEGF D и плацентарный фактор роста [124, 125]. VEGF А играет ведущую роль в регуляции ангиогенеза. Синтез этого фактора активируется в условиях гипоксии за счет увеличения периода полураспада матричной мРНК, а также за счет усиления транскрипции гена. При длительно существующей ишемии происходит накопление как самого фактора, так и мРНК, что доказывает положительную обратную связь между ишемией и синтезом VEGF $[125,126$, $127,128]$.

Повышение VEGF обусловливает повреждение сосудистой стенки, повышая их проницаемость и усиливая пролиферацию эндотелиальных клеток с формированием микроаневризм, а в пролиферативной стадии - рост новообразованных сосудов $[129,130]$. Вышеизложенное дает основание полагать, что экспрессия VEGF проходит последовательные фазы в зависимости от стадии основного заболевания. VEGF А является не только ведущим фактором ангиогенеза, но и критерием прогноза сосудистых катастроф в организме человека [131].

Роль семейства VEGF и TNF- $\alpha$ в развитии различных патологических процессов, в том числе и КМП изучена недостаточно, многие аспекты влияния этих факторов на развитие и течение КМП требуют дальнейшего изучения.

При гипоксии повышается уровень гипоксия-индуцибельного фактора-1альфа (HIF-1 $\alpha)$, который активирует его экспрессию. VEGF повышает 
проницаемость сосудов, ведет к дезорганизации сосудистой стенки $[124,125$, $126,128]$.

Анализ результатов показал, что у детей с КМП уровень VEGF превышал нормальные значения в 2-4,5 раза у 95,5\% больных (рис.4).

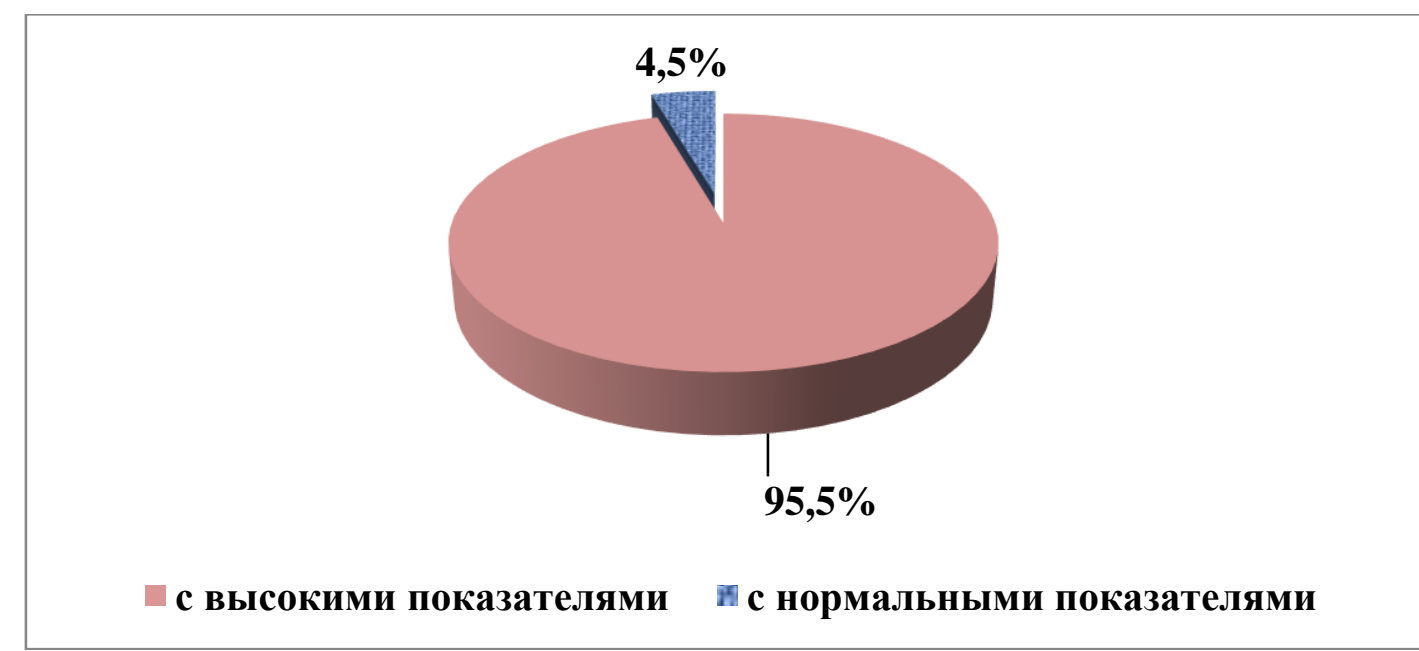

Рис.4. Количество детей с высоким и нормальным содержанием VEGF в сыворотке крови.

С целью определения признаков ремоделирования миокарда нами изучены структурно-функциональные характеристики миокарда ЛЖ у обследованных детей, которые показали сохранность нормальных показателей морфологии миокарда лишь у 7,9\% больных с КМП. Структурно-функциональные изменения миокарда ЛЖ проявлялись развитием асимметричной и симметричной гипертрофией межжелудочковой перегородки, гипертрофией верхушечной, задне-перегородочной или боковой стенки левого желудочка и увеличением массы миокарда у 34,6\% больных, а также уменьшением полости левого желудочка, связанное с гипертрофией миокарда, который является морфологическим признаком ГКМП и одним из факторов, способствующих нарушению гемодинамики за счет недостаточного наполнения левого желудочка во время диастолы. Развитие гипертрофии миокарда ЛЖ сопровождалось снижением величины фракции выброса за счет отсутствия активации компенсаторных возможностей миокарда. Дилатационные изменения левого желудочка выявлены почти у 46\% детей с ДКМП и левого предсердия у 11,5\% детей с ГКМП. Это сопровождалось снижением показателей сократимости 
левого желудочка (ФВ ЛЖ<30—40\%), митральная и трикуспидальная регургитация, нарушение диастолической функции левого желудочка за счет удлинения фазы его изометрического расслабления и повышения конечного диастолического давления в его полости.

Корреляционный анализ сывороточного содержания изученных цитокинов показал тесную корреляционную зависимость их концентраций от степени эхокардиографических изменений сердца. У детей с СН при ДКМП выявлена зависимость степени дилатации ЛЖ от уровня IL-1 $\beta$ и IL-6: конечного диастолического размера (КДР) от концентрации IL-1 $\beta$ (КДР-IL1 $\beta, \mathrm{r}=0,52$; $\mathrm{p}<0,05$. Установлена обратная связь между параметром фракции изгнания и IL-6 $(\mathrm{r}=-0,48)$.

Таким образом, нейрогормональный маркер эндотелин-1, маркеры воспаления IL-1 $\beta$, IL-6, TNF- $\alpha$ и эндотелиальный фактор роста VEGF являются диагностическими и прогностическими критериями развития и прогрессирования кардиомиопатий и сердечной недостаточности независимо от варианта кардиомипатий. Данные биомаркеры играют важную роль в прогрессировании сердечной недостаточности, определяя интенсивность процессов ремоделирования миокарда посредством регулирования уровня апоптоза и следующего за ними заместительного фиброза в сердце, что является причиной нарушения его структуры и несостоятельности сократительного аппарата при прогрессировании сердечной недостаточности. Дальнейшее изучение биомаркеров в развитии и прогнозировании КМП и СН позволит понять их комплексное воздействие на организм и получить данные по определению новых биологических критериев прогнозирования течения и исходов КМП у детей. 